\title{
Socialismo y anarquismo en la formación de la clase obrera en Argentina: problemas historiográficos y apuntes metodológicos
}

\author{
Lucas Poy \\ UBA-CONICET
}

Cierto sentido común historiográfico ubica la aparición de la "cuestión social" en nuestro país en los primeros años del siglo XX, debido al indudable salto de la conflictividad representado por la primera huelga general y respondido con la sanción de la Ley de Residencia. Es importante no perder de vista, sin embargo, que el proceso de delimitación de una identidad obrera, de desarrollo de sociedades gremiales permanentes y de agitación huelguística sistemática se remonta por lo menos a finales de la década de 1880, cuando ya la ciudad de Buenos Aires era testigo de una profunda movilización de los trabajadores que sorprendía a los contemporáneos. Una mirada atenta a los acontecimientos de esos tres lustros finales del siglo pone de manifiesto que el proceso de desarrollo del movimiento obrero y la izquierda fue, particularmente en la ciudad de Buenos Aires, muy vertiginoso. Hacia mediados de la década de 1880 , el país ya había sufrido un proceso de transformaciones profundas que habian dado lugar a una creciente población trabajadora, de origen mayoritariamente inmigrante. Sin embargo, eran prácticamente desconocidas todavía las organizaciones y las huelgas: no por casualidad la prensa insistía en la supuesta inexistencia de una "cuestión obrera" en el país. Una década más tarde, un observador que hubiera visitado el país en la primavera de 1896, cuando una enorme movilización huelguística recorrió a los principales sectores obreros, no solo en Buenos Aires sino también en otras ciudades del interior, no podría haber dejado de advertir que la situación habia cambiado sustancialmente. Decenas de sociedades de resistencia y varios intentos de formar una federación, un partido socialista casi definitivamente constituido, numerosos nucleamientos anarquistas, varios periódicos obreros, decenas de huelgas e incluso una casi general, habian colocado a la clase trabajadora como un actor ya insoslayable en la vida del país. Se trató de una década, por otra parte, que estuvo marcada por la mayor crisis económica que hubiera conocido el país hasta entonces: al colapso de 
1890 lo siguió todo un lustro de dificultades económicas con enorme impacto social. La aparición en escena de la clase trabajadora fue un producto de estos años convulsionados.

Dentro de la amplia producción historiográfica sobre la historia del movimiento obrero y la izquierda en la Argentina, aquellos trabajos que tomaron como objeto de estudio el problema de los orígenes y los primeros pasos de las organizaciones obreras y las fuerzas de la izquierda en nuestro país -nos referimos particularmente a aquellos que abordan las últimas décadas del siglo XIX-constituyen un núcleo temático propio y con una importante trayectoria. En la medida en que, como veremos a continuación, los primeros trabajos dedicados a la historia del movimiento obrero y la izquierda provinieron de autores pertenecientes a fuerzas políticas activas en ese mundo del trabajo, la inquietud sobre los orígenes estuvo presente en casi todas las miradas que se trazaban sobre un pasado en el cual se rastreaba el desarrollo de la propia corriente política a la cual pertenecía el autor. En años posteriores, cuando la historiografia sobre la izquierda y los trabajadores en el país se amplió y se enriqueció, la referencia a las etapas tempranas, si bien de manera desigual, continuó estando presente.

A lo largo de los años, de todas formas, la historiografía abordó de maneras muy diversas los diferentes aspectos que hacen a la historia de este periodo temprano. En particular resulta interesante advertir el modo en el que se planteó el vínculo entre la historia de los trabajadores -entendida ésta en un sentido amplio que incluye tanto los análisis políticos sobre las vicisitudes de la historia del movimiento obrero y sindical como los estudios sobre aspectos de la vida social, económica y cultural de los trabajadores- y la historia de la izquierda, tanto desde una perspectiva anclada en el desarrollo social y politico de las principales fuerzas activas en el período como en la clave de una historia intelectual de las ideas y posicionamientos de dichos actores. En la mayor parte de los casos, como veremos, la historia de los orígenes de la izquierda y la del proceso de conformación de la clase trabajadora local se desarrollaron en niveles separados, en ocasiones incapaces de dialogar entre sí. En este trabajo planteamos una mirada de conjunto a la historiografia existente sobre los origenes del movimiento obrero y una serie de planteamientos metodológicos sobre lo que creemos un modo enriquecedor de abordar el estudio del desarrollo de las primeras corrientes políticas de izquierda al calor del proceso de estructuración de la clase obrera en Argentina en las últimas décadas del siglo XIX. 


\section{La historiografia sobre los origenes de la izquierda y la clase obrera en Argentina}

Como es sabido, durante un extenso período los pocos trabajos sobre historia de los trabajadores fueron obra de autores vinculados de manera directa con las corrientes políticas de la izquierda. Si en una primera etapa estas lecturas aparecieron en forma de breves folletos o artículos en diferentes publicaciones partidarias, algunos años más tarde comenzaron a publicarse los primeros libros "clásicos" en la materia, conocidos en la historiografia como las obras de los "historiadores militantes". Dentro del campo del anarquismo, más allá de algunos pioneros aportes de Max Nettlau (1927), fue Diego Abad de Santillán (1930, 1933) quien publicó un conjunto de trabajos centrados en recuperar la experiencia de la FORA, que incluían de todos modos una reflexión más amplia sobre el movimiento obrero del período y sobre otras fuerzas políticas que intervenian en el mismo. Sus obras nos acercan una interpretación que reivindicaba al anarquismo de vertiente organizadora y, en particular, al grupo de militantes que editaba el periódico La Protesta, núcleo al cual él mismo pertenecía. Algo similar ocurrió con diversos autores vinculados al Partido Socialista: si bien Jacinto Oddone (1934, 1949) fue el más destacado, con una historia del socialismo y otra del movimiento sindical argentino en la etapa previa al peronismo, hubo en esos años muchos otros dirigentes y militantes socialistas que publicaron memorias, trabajos históricos de relevamiento del pasado de su propia corriente política, y particularmente obras de reivindicación de Juan B. Justo. Algunas décadas más tarde aparecieron los volúmenes de Sebastián Marotta (1960, 1961, 1970), que conforman la historia "canónica" de la corriente sindicalista revolucionaria y posiblemente la mejor y más documentada de las "historias militantes" elaboradas a lo largo de esas décadas. ${ }^{1}$

Fuertemente marcadas por una perspectiva apologética del pasado de la propia corriente politica a la cual pertenecía el autor, estas interpretaciones tendian a omitir las complejidades del desarrollo de esas fuerzas politicas y sus fuertes polémicas internas, empobreciendo así el análisis de este período temprano. Más allá de estos límites, hay que señalar que la fuerte crítica que se ensañó, años más tarde, con estos

1. Para un análisis extenso de la historiografia del Partido Socialista, ver Camarero y Herrera (2005), Poy y Gaido (2011a). Desde las filas del Partido Comunista se elaboraron varios trabajos, aunque posiblemente el más destacado sea el de Rubens Iscaro (1958): su obra dedicó, no obstante, menos espacio que las de otros historiadores militantes a este período temprano de la historia del movimiento obrero. 
historiadores militantes por no cumplir ciertas "reglas del oficio" de la historiografia profesional -a la cual, por otra parte, éstos no tenían pretensiones de pertenecer- suele hacer perder de vista que sus trabajos representaron obras pioneras en un terreno que hasta entonces permanecía absolutamente inexplorado. En no pocas ocasiones, además, se trató de trabajos de importante rigor, que contaban con acceso a material documental que luego se perderia, dejando de estar al alcance de los investigadores.

La riqueza de los aportes de estas clásicas "historias militantes" se destaca aún más cuando se las compara con los trabajos aparecidos desde otro ángulo del espectro político, a partir de la década de 1950, que buscaron analizar la historia del movimiento obrero y las corrientes politicas de izquierda desde la perspectiva del llamado revisionismo histórico. En los casos en que analizaron el período de formación del movimiento obrero, la mayoría de las obras revisionistas tendió a considerar a las corrientes socialistas y anarquistas como "flores exóticas" llegadas del extranjero, que se adaptaban mal a los intereses de una clase obrera argentina que sólo habría encontrado su representación más auténtica -e incluso surgido como tal- con el movimiento peronista. Los trabajos del revisionismo se planteaban como el reverso de la moneda de las obras clásicas de los historiadores de izquierda, en la medida en que también desarrollaban una abierta toma de posición política pero centrada no en reivindicar sino en reducir la importancia histórica de las fuerzas que habían tenido un papel hegemónico en el movimiento obrero antes de la aparición del peronismo. A diferencia de aquéllos, no obstante, los revisionistas elaboraron trabajos de escasa calidad en el campo de la historia de los trabajadores: el carácter polémico hacia las corrientes de izquierda ocultaba mal una falta de rigor historiográfico e incluso de manejo de las fuentes del período. En tanto consideraban que la clase obrera no se habría constituido como tal sino hasta la aparición del peronismo, estos abordajes eran incapaces de advertir el complejo proceso de estructuración de la misma como sujeto social y político independiente en un período mucho más temprano de la historia del país.

En la década de 1960 el interés por el estudio de los trabajadores comenzó a llegar al campo académico: si bien el interés de los nuevos investigadores se concentró sobre todo en un período posterior y particularmente en discusiones sobre los orígenes del peronismo, se realizaron algunos importantes aportes sobre el proceso inmigratorio y la estructuración de la clase trabajadora en las últimas décadas del siglo XIX. Entre fines de los 60 y comienzos de la década siguiente aparecieron algunos trabajos históricos dedicados específicamente a los orígenes del movimiento obrero (Panettieri, 1967; Godio 1972), mientras que la 
historiografia "militante" siguió contribuyendo con algunas producciones dedicadas más específicamente a los orígenes del socialismo argentino, como consecuencia de la ruptura politica en el interior del Partido Comunista. $^{2}$ Durante la década de 1970 , en tanto, aparecieron algunos importantes aportes de investigadores extranjeros. Mientras el israelí Iaacov Oved (1976, 1978) y el español Gonzalo Zaragoza (1976, 1978, 1996) publicaron los primeros trabajos "profesionales" sobre el origen del anarquismo argentino, el norteamericano Richard Walter (1977) editó una historia general del Partido Socialista desde sus origenes hasta la década de 1930.

Si estos autores extranjeros mostraban un interés por la historia política de los orígenes del movimiento obrero y de las corrientes de izquierda que intervenian en él, durante esos años aparecieron también trabajos como el de Guy Bourdé (1973), que se orientaban a estudiar las condiciones de vida y trabajo de la población inmigrante de fines del siglo XIX. Otro trabajo pionero en este sentido fue el de Leandro Gutiérrez (1981), quien planteó una agenda de trabajo que fue parcialmente tomada en los años posteriores a 1983, cuando tuvo lugar un importante desarrollo historiográfico del área a partir de una serie de nuevas formulaciones que colocaron en primer plano a la historia de los trabajadores como un tema de interés para la investigación profesional. Este renovado interés por la historia de los trabajadores se enmarcó en un intento de renovación historiográfica que combinaba una valorización de la historia social marxista británica y la experiencia francesa de la escuela de Annales con una reivindicación de la profesionalización del historiador que se suponía debía verse acompañada con una cierta "objetividad", resultado del alejamiento respecto a fuertes adscripciones políticas. Se planteó así un escenario en el cual, al mismo tiempo que la historia de la clase trabajadora ocupaba por primera vez un lugar destacado en la agenda de la historiografia profesional, cobraba fuerza

2. El maoísta José Ratzer (1970), criticando lo que consideraba una "linea reformista" originada en Juan B. Justo y adoptada más tarde por el PCA, reivindicó al ingeniero alemán Germán Avé-Lallemant como el principal teórico de un marxismo "ortodoxo" y revolucionario que habría cobrado fuerza durante los primeros años de la década de 1890 para perder terreno luego ante el avance del reformismo de los líderes del Partido Socialista. Cinco años más tarde, Leonardo Paso (1974) -vinculado al Partido Comunista- respondió a Ratzer con una compilación de artículos de Lallemant, que incluía una introducción de su autoría en la que también reivindicaba la pertenencia de Lallemant a una tradición "revolucionaria" opuesta al reformismo de Justo; señalaba, no obstante, que dicha tradición estaba encarnada por el Partido Comunista del cual formaba parte. Sobre Lallemant y el papel de los socialistas alemanes, ver Poy y Gaido (2011b). 
una suerte de "sentido común" académico que miraba con recelo la toma de posición política del investigador, en particular si ésta se procesaba en las filas de la izquierda o de las organizaciones obreras.

Así, si bien la renovación historiográfica recuperaba explícitamente la experiencia de la historia social británica y de autores como Edward P. Thompson o Eric Hobsbawm, su lectura se realizaba desde un posicionamiento académico-político distinto: el alejamiento respecto a cualquier ámbito de militancia en las filas de los trabajadores, en los historiadores de la renovación historiográfica argentina de la década de 1980, era sustancialmente mayor que el de los autores británicos que pretendian tomar como referencia. En parte como consecuencia de ello, el cuestionamiento a la "historiografía militante" ocupó un lugar más destacado y el tópico de la crítica a las obras centradas en la historia política del movimiento obrero y la izquierda cobró fuerza para convertirse en uno de los ejes más comunes de los nuevos trabajos, al tiempo que se reivindicaba el valor de los llamados "estudios culturales" desarrollados por diversos autores también del ámbito anglosajón.

La renovación historiográfica se trazó entonces, como un objetivo general, promover un análisis que corría del centro del análisis tanto la historia de la izquierda como el estudio de los conflictos y huelgas y ponía el énfasis en diferentes aspectos vinculados a la estructuración histórica de la clase trabajadora como grupo social. Se trató, de todas formas, de una producción heterogénea entre sí: si bien compartian una serie de inquietudes generales, las investigaciones se orientaron en diversas direcciones y abordaron, con mayor o menor nivel de desarrollo, distintas problemáticas. Si los trabajos dedicados a analizar el proceso de industrialización y de transformación económica en un sentido global fueron escasos, resultaron en cambio más abundantes los estudios sobre el proceso específico de conformación del mercado de trabajo, el masivo flujo inmigratorio, las sociedades de socorro mutuo o las primeras respuestas que surgieron desde el Estado ante la novedosa existencia de una "cuestión social" en un país que se creía exento de ella. Se realizaron avances pioneros en la historia de las mujeres trabajadoras, que habian quedado casi siempre al margen de cualquier reflexión en las antiguas historias "militantes", y sobre el trabajo de los menores, que ocupaban un lugar fundamental en la fuerza de trabajo del período. Siguiendo el camino en parte abierto por el trabajo ya mencionado de Leandro Gutiérrez, fueron particularmente importantes los aportes realizados en el terreno de un análisis de las condiciones de vida, trabajo y vivienda de los trabajadores en este período temprano.

Si uno de los rasgos característicos de esta renovación historiográfica era, como vimos, una menor preocupación por la historia política de la izquierda e incluso del movimiento obrero, uno de sus principales 
referentes, Luis Alberto Romero (1987) avanzó incluso en un cuestionamiento a la propia utilización del concepto de "clase obrera". Con una perspectiva que sostenía que la utilización de las herramientas de la historia social y los estudios culturales debía implicar un abordaje complejo que superase lo que se consideraba una restrictiva lectura en términos de clase propia del marxismo, Romero argumentó que el concepto de "sectores populares" era el que mejor se adecuaba para el análisis de los grupos sociales subalternos en nuestro país fundamentalmente a partir del período de entreguerras, caracterizado según esta interpretación por una importante posibilidad de ascenso social. Según esta lectura, el período previo a los gobiernos radicales habría estado marcado por un mayor peso de una identidad clasista que luego se habría diluido para dar lugar a una más ambigua agregación de "sectores populares", concepto cuya utilización, por otra parte, solía defenderse como más "rico" que el de "clase obrera". En la importante tesis de Juan Suriano (2001) sobre el anarquismo se ponían de manifiesto buena parte de estos puntos de vista: por un lado porque se promovia un análisis del movimiento libertario menos centrado en los debates políticos que en su despliegue como fenómeno social e incluso cultural; por el otro porque una conclusión fundamental del trabajo era la que interpretaba el declive del anarquismo en el periodo posterior a 1910 como una consecuencia de esas transformaciones sociales que estaban diluyendo la delimitación de una "clase obrera" excluida de mayores posibilidades de ascenso social y para la cual el anarquismo era una expresión política adecuada.

Sería un error, de todas maneras, dotar de una extrema homogeneidad a una producción historiográfica que conoció matices. Es interesante observar, en este sentido, que en algunos casos las diferencias de enfoque también estaban relacionadas con las trayectorias de los autores que las desenvolvieron: fueron, en efecto, dos investigadores que provenían de filas "militantes" quienes elaboraron varios trabajos de características académicas y ancladas en el nuevo contexto de renovación pero que mantenían una preocupación mayor por elaborar una perspectiva de análisis global sobre los origenes del "movimiento obrero" y no soslayaban la historia política de la izquierda. Es el caso de Ricardo Falcón, militante trotskista durante su juventud en los años sesenta y setenta, quien debió exiliarse durante la dictadura y completó sus estudios en Europa, desarrollando su investigación doctoral en los archivos del Instituto de Historia Social (IISG) en Holanda. Uno de sus primeros trabajos, publicado durante la dictadura (1979), mostraba un interés por la historia política del socialismo argentino en sus años iniciales. Su propia tesis doctoral pretendió desarrollar una historia de los orígenes del "movimiento obrero": si bien compartía con 
los autores de la renovación que caracterizó a los ochenta una inquietud por colocarse en el terreno de la historia social e incluso cultural, mantenía una preocupación por la historia política de las corrientes activas en el seno del movimiento obrero que lo coloca en cierta forma en la tradición de los historiadores militantes, carácter que él mismo compartía por lo menos hasta comienzos de la década de 1980. Algo similar ocurre con los trabajos de Edgardo Bilsky (1984, 1985, 1992), quien de hecho compartía militancia con Ricardo Falcón -en la corriente que antecedió al actual Partido Obrero- y también debió exiliarse y completar sus estudios en Europa. Sus trabajos sobre la FORA y sobre la Semana Trágica compartian la inquietud por una historia social de los orígenes del movimiento obrero argentino que utilizase el concepto de "clase obrera" y no perdiese de vista tampoco una discusión de las estrategias de las corrientes politicas de la izquierda, motivo por el cual fue criticado en alguna ocasión por Leandro Gutiérrez y Luis Alberto Romero (1991), en un trabajo que pretendía trazar el cuadro general de la historiografia sobre el tema y tomaba la obra de Bilsky como una expresión de la persistencia de cierto "molde historiográfico construido fuera del campo académico", que era visto como una rémora del período dominado por la historiografia militante. ${ }^{3}$

La importante renovación historiográfica que tuvo lugar luego de 1983 comenzó a orientarse hacia otras áreas temáticas antes de consolidar un corpus sólido sobre los orígenes del movimiento obrero en nuestro país: con algunas excepciones, como Juan Suriano, Mirta Lobato o Ricardo Falcón, que siguieron investigando en el campo de la historia de los trabajadores, la mayor parte de los autores que habian enriquecido la renovación historiográfica de los ochenta se pasaron a otras temas, en lo que el propio Suriano (2006) caracterizó como "una fuga masiva de investigadores hacia el campo de la historia politica". Fue un trabajo anclado en la historia intelectual más que en la historia social -el de José Aricó (1999)- el que reorientó en cierta medida los trabajos sobre la historia de la izquierda: su ensayo dedicado al fundador y principal dirigente del Partido Socialista argentino planteaba una reivindicación de la figura de Juan B. Justo, en tanto lo consideraba capaz de haber articulado una "hipótesis" original para la traducción del socialismo a la

3. Sobre su investigación realizada en el IISG de Amsterdam decían que "si su sensibilidad de historiador profesional le permite vislumbrar, a principios de siglo, el carácter todavía amorfo de una sociedad en proceso de constitución, no solo en términos sociales sino de experiencias compartidas, actitudes, opiniones e ideologias, sus convicciones lo llevan a postular la necesaria constitución de ese actor indefinido en clase y a fundamentar su asunción en las premisas ideológicas de los militantes" (1991: 111, subrayado nuestro). 
problemática de la Argentina de principios de siglo. Su trabajo tuvo un fuerte impacto no sólo en el campo de los estudios sobre el socialismo argentino sino en un plano más general en el terreno de los análisis sobre la "recepción" del marxismo en América Latina. En los últimos años aparecieron una serie de trabajos que, colocándose en cierta forma en el sendero abierto por Aricó, dan muestra de un interés por recuperar un análisis de las corrientes políticas que intervinieron en los orígenes del movimiento obrero y particularmente de las agrupaciones socialistas y vinculadas al marxismo. La aparición de un conjunto de artículos en la revista Politicas de la Memoria contribuyó en primer término a volver a poner a los primeros núcleos socialistas en el centro de atención de la investigación académica (Martínez Mazzola, 2004; Tarcus, 2004, 2007b; Zeller, 2007). Aunque más enfocada en el siglo XX, la compilación de artículos sobre la historia del Partido Socialista argentino editada por Carlos Herrera y Hernán Camarero (2005) marcó otro paso adelante en esta renovación del interés por la historia política de la izquierda. Otro aporte es la publicación de Marx en la Argentina, de Horacio Tarcus (2007a) que constituye una referencia insoslayable para el estudio de los orígenes del socialismo en nuestro país. Elaborado originalmente como parte de su tesis doctoral, presentada en la Universidad de La Plata, el libro de Tarcus desarrolla un análisis de los principales agrupamientos y dirigentes del socialismo argentino en el último tercio del siglo XIX y la primera década del siguiente. Con una perspectiva más anclada en la historia intelectual que en la historia social, Tarcus analiza el problema de la "recepción" del marxismo en las periferias -siguiendo en este punto las inquietudes de José Aricó- y en ese sentido el libro profundiza menos en la cuestión de la vinculación de los agrupamientos socialistas con las organizaciones obreras que en las particularidades de sus planteamientos políticos y teóricos. ${ }^{4}$

\section{Un balance}

El balance de la historiografia sobre los orígenes del movimiento obrero y la izquierda en nuestro país arroja un saldo contradictorio. Por una parte, el tema parece estar recobrando actualidad en los últimos años, con la aparición de nuevos trabajos dedicados a recuperar un análisis de las corrientes de izquierda. Por otra parte, no puede dejar de señalarse

4. Aportan en este mismo sentido la reciente aparición de un Diccionario biográfico de la izquierda (Tarcus, dir., 2007) y de una antologia bilingüe del Vorwärts, periódico que fue editado entre 1896 y 1901 por socialistas alemanes residentes en Buenos Aires y constituye una fuente fundamental para el periodo, hasta ahora prácticamente inexplorada (Tarcus, Zeller, Carrera, 2008). 
que la "historia de los trabajadores" ha perdido la centralidad que supo tener hace un par de décadas -aun con los matices y contradicciones ya apuntadas-, en un contexto en el cual las inquietudes de la mayoria de los historiadores parecen orientarse hacia los estudios del régimen político, la opinión pública, la construcción de la ciudadanía, etc.

Los aportes de la historiografia sobre el periodo de los origenes son menos abundantes de lo que podría sugerir el amplio espectro de trabajos sobre el "mundo de los trabajadores" anterior al Centenario que acabamos de presentar. Ocurre que un rasgo común a la mayor parte de las investigaciones, de una u otra perspectiva historiográfica, fue colocar lo sucedido en ese período en el plano de un análisis de los "antecedentes" de la historia del movimiento obrero antes que como un objeto de estudio específico. Se trató de un rasgo compartido tanto por las viejas "historias militantes" como por la más reciente historiografia académica: si en las primeras lo ocurrido antes de mediados de la década de 1890 era analizado en clave de antecedentes del proceso de formación del Partido Socialista, de las primeras centrales obreras o de los agrupamientos anarquistas que se consolidarian en la década del 900, en la segunda se generalizó una interpretación que ubicaba la aparición definitiva de una "cuestión social" en los primeros años del siglo, particularmente con la sanción de la Ley de Residencia en el año 1902. El período previo, por lo tanto, ocupó un espacio sustancialmente menor en la mayor parte de las investigaciones, y no fueron pocas las que explícitamente señalaron que hasta comienzos del siglo XX la conflictividad obrera no supuso un factor de importancia en la escena política de la ciudad de Buenos Aires y del país. El hecho de que, por lo general, los trabajos que se planteaban trazar un análisis en clave de "orígenes del movimiento obrero" tomaran como punto de referencia inicial la fundación de la Sociedad Tipográfica Bonaerense, en 1857, no implicaba un mayor desarrollo del análisis sobre esta etapa: en efecto, debido a la escasez de fuentes documentales y a las escasas investigaciones realizadas, los trabajos se limitaron a trazar algunos grandes hitos de esa "prehistoria" del movimiento obrero que permanecía en buena medida desconocida.

El trabajo de Ricardo Falcón es posiblemente el que llegó más lejos en el intento de trazar un cuadro de conjunto sobre el problema: su investigación buscó remontarse a la década de 1850 y realizó importantes aportes respecto al período de influencia de militantes vinculados a la Primera Internacional que han sido ampliados en el último libro de Horacio Tarcus. De todas formas, debido a su intención de abordar un período tan amplio -casi cuarenta años-, el libro de Falcón no llegó en muchos puntos más que a abrir importantes líneas de trabajo con aportes sugestivos, que posteriormente no han sido retomados en una 
obra de esa escala. Si el análisis de la situación estructural del mercado de trabajo y las condiciones de vida y trabajo de la población trabajadora son objeto de un tratamiento cuidadoso, hay otros aspectos de gran importancia, como los ciclos de agitación huelguística de 1888-1889 y 1894-1896 o la estructuración de las principales sociedades de resistencia en esa década, que son apenas mencionados, sin un análisis en profundidad que resulta esencial para periodizar con precisión el proceso de delimitación de una conciencia de clase entre los trabajadores de la urbe. ${ }^{5}$ Juan Suriano publicó un importante artículo (2003) donde advertía la trascendencia del impacto que tuvo sobre la clase trabajadora la coyuntura decisiva de 1890, cuando el país enfrentó la peor crisis económica de su historia, pero la investigación sobre el tema no fue profundizada, y la mayor parte de las obras sobre esos años decisivos siguieron siendo las que analizaban, de manera más o menos aislada, la celebración del $1^{\circ}$ de Mayo, la formación de los primeros grupos socialistas o la actividad de dirigentes como Germán Ave-Lallemant, sin avanzar en trazar un cuadro de conjunto sobre la vinculación existente entre esos importantes aspectos de la historia política de los trabajadores y la dinámica de conflictividad social y transformaciones económicas del período. El mayor avance en este último terreno fue un artículo de Ronaldo Munck (1987) que buscó trazar un cuadro general sobre la evolución de los principales ciclos de agitación obrera en esta etapa. El reciente trabajo de Tarcus, como señalamos más arriba, se concentra en un análisis de la "recepción de Marx" en el país, proponiendo un ensayo de historia intelectual que realiza aportes sobre los posicionamientos y debates del naciente socialismo local en el periodo objeto de nuestro estudio pero no profundiza en una discusión sobre los vínculos de los militantes socialistas con el movimiento obrero y su relación con los principales ciclos de agitación huelguística.

\section{Socialismo y anarquismo en la formación de la clase obrera argentina: apuntes metodológicos para una interpretación de conjunto}

Consideramos que una perspectiva enriquecedora para reconstruir la historia de ese período de fundamental importancia para el desarrollo de la izquierda y el movimiento obrero requiere recuperar aspectos abordados en la historiografia previa e incluirlos en una interpretación de

5. Poco antes de su muerte, Falcón estaba trabajando en un libro sobre los orígenes del socialismo local, que quedó incluso. Los Cuadernos del CIESAL han publicado algunos fragmentos en su último número (Falcón, 2011). 
conjunto. Se trata, desde nuestro punto de vista, de estudiar el problema de la formación de la clase obrera de Buenos Aires con una perspectiva que no lo entienda solamente como una cuestión de orden sociológico ni como un mero estudio político del movimiento sindical. En efecto, entendemos que es fundamental desarrollar un análisis que ponga en relación el proceso de luchas y enfrentamientos de la clase trabajadora con el desarrollo de las corrientes políticas que intervenían en ese movimiento, a fin de estudiar las vinculaciones mutuas entre ambos fenómenos. No se trata de buscar, como hizo cierta historiografia "oficial" del socialismo, de qué manera la actividad de algunos dirigentes exiliados contribuyó a "crear" al movimiento obrero argentino; pero tampoco de soslayar la relación existente entre la construcción de organizaciones obreras en el contexto del enfrentamiento social y la consolidación de agrupamientos políticos.

El estudio de la conformación de la clase obrera no puede prescindir de un análisis de las transformaciones estructurales que conoció la sociedad argentina en el último tercio del siglo XIX: fue un producto del desarrollo del capitalismo dependiente que tuvo lugar en Argentina a fines del siglo XIX, con el correlato de la conformación de un mercado de trabajo capitalista de características peculiares, el cierre de las perspectivas de "ascenso social" de los recién llegados y un cuadro general que mostraba un incremento en la explotación. A lo cual se agrega el cuadro de grave crisis capitalista de los años 1890-1893, con sus consecuencias: una grave carestía, primero; desocupación, miseria y emigración, más tarde; concentración y centralización de capitales, ruina de pequeños propietarios y artesanos, etc. En otros términos, es el desarrollo del capitalismo en Argentina, y en particular su primera gran crisis, lo que está en la base y condiciona el desarrollo de la clase obrera. Una de nuestras hipótesis principales es que la crisis económica que estalló en el país hacia 1889-1890 puso de manifiesto los límites que habian surgido a la integración económica y social de los inmigrantes y creó las condiciones para una creciente agitación social en la ciudad, que conoció un salto significativo en los años 1888-1896 y dio lugar a la consolidación de organizaciones permanentes de trabajadores, contribuyendo así a definir, a través de un proceso de movilización, la presencia de la clase obrera en la sociedad argentina.

Ocurre que el análisis de las transformaciones estructurales no basta para explicar el proceso de conformación de la clase obrera: es indispensable además estudiar el proceso de enfrentamientos sociales a partir del cual esos trabajadores comenzaron a forjar una experiencia colectiva como clase. Si en la década de 1870 y buena parte de la siguiente vemos que todavia la conflictividad obrera es esporádica y no logran consolidarse organizaciones permanentes, desde fines de la década de 1880 
tuvo lugar un proceso muy acelerado de agitación obrera en la ciudad de Buenos Aires al calor del cual se consolidó la formación de la clase trabajadora. Durante esos años vemos cómo la clase obrera avanzó en diferentes "grados de unidad": si en el ciclo huelguístico de 1888 y 1889 fueron fundamentalmente los trabajadores de una empresa o de un determinado oficio los que salian a la lucha en reclamo de un aumento salarial o en defensa de sus primeras organizaciones, en el marco del ascenso obrero de 1894-1896 observamos que ya eran dominantes los reclamos por la reducción de jornada y contra el trabajo a destajo, al tiempo que se producian mayores acciones conjuntas de distintos oficios hasta llegar a una virtual huelga general en 1896.

Durante todo el período se observa cómo la conflictividad de unos gremios actuó como un fermento para la movilización de trabajadores de otros oficios: si en muchos casos se trataba de un "contagio" que tenía que ver con los vínculos que existian entre trabajadores de diferentes ocupaciones debido a las características estructurales de un mercado de trabajo donde la estacionalidad y la inestabilidad laboral hacian que para muchos trabajadores el paso de un oficio a otro fuera habitual, en otras ocasiones se observa que ese "contagio" alcanzaba a trabajadores sin vínculos previos en la esfera de las actividades productivas, lo cual pone de manifiesto el papel que jugaba la experiencia de los enfrentamientos sociales a la hora de delimitar una identidad clasista entre los trabajadores de la ciudad.

Es aqui donde resulta fundamental vincular el estudio de la génesis del movimiento obrero con el análisis de los orígenes de la izquierda en nuestro país, en la medida en que los militantes de estas fuerzas políticas jugaron un papel muy activo en este proceso. En tanto la formación de la clase obrera argentina se produjo en un período posterior al de otros países, y al mismo tiempo en el marco de una masiva inmigración europea, las corrientes políticas activas en el seno del movimiento obrero a nivel internacional tuvieron su influencia en nuestro país desde una fecha muy temprana y deben ser consideradas un actor fundamental que contribuyó a ese proceso acelerado de delimitación de una identidad de clase. La primera generación de militantes políticos llegados al país, vinculados a la experiencia de la Primera Internacional, encontró dificultades para su desarrollo debido al cuadro aún embrionario de consolidación de la estructura capitalista y de un proletariado aún en formación. Hacia mediados de la década de 1880, como señalamos, ya las condiciones "estructurales" habian cambiado y los militantes de la izquierda encontraron un campo de acción mucho más amplio. Todo un grupo de anarquistas, vinculados con los italianos Errico Malatesta y Ettore Mattei, jugaron a partir de 1885-1886 un papel importante en el proceso de movilización obrera en la medida en que buscaron 
ligar su acción al de las nacientes organizaciones gremiales, e incluso con los militantes socialistas, introduciendo en múltiples reuniones y asambleas obreras planteamientos de delimitación clasista. En algunos casos, como en la sociedad de panaderos, fueron ellos mismos los protagonistas del proceso de creación de sociedades. A pesar de que el planteo clasista ocupaba en su programa un lugar secundario y que se oponian a la construcción de sociedades gremiales por considerar que se trataba de un objetivo "reformista", incluso los militantes anarquistas contrarios a la organización, nucleados en torno a El Perseguido y mayoritarios en la primera mitad de la década de 1890, jugaron un rol importante en el proceso de formación de la clase obrera local. Su actividad fue importante en el sentido de profundizar las tendencias existentes en todo un sector de la clase obrera para romper sus vínculos con sociedades policlasistas, de base nacional o étnica, y estimular una radicalización política que, en un contexto de grave crisis económica y social, trazó una fuerte separación entre los obreros y otros grupos sociales de la ciudad.

Los militantes socialistas tuvieron un protagonismo indiscutible en la delimitación de una identidad obrera: su agitación política insistía tenazmente en la necesidad de que los trabajadores se dieran una organización política propia e independiente, particularmente a partir del impulso dado por las resoluciones del congreso de Paris de 1889 que llevaron a la organización de un meeting $\mathrm{el} 1^{\circ}$ de Mayo del año siguiente. Los socialistas desarrollaron en forma permanente, además, una propaganda en pro de la organización de sociedades de resistencia e incluso de federaciones de gremios. Los planteos de la primera Federación Obrera de 1890-1892, en sus reclamos a los poderes públicos, aun cuando no lograron obtener resultados provechosos, tuvieron el indudable mérito de plantear el programa de reivindicaciones que amplios sectores gremiales tomarian en los años inmediatamente posteriores: jornada de ocho horas, abolición del trabajo a destajo, legislación protectora del trabajo, etc.

El vínculo entre izquierda y clase obrera, por otro lado, debe ser analizado en ambas direcciones. Del mismo modo que señalamos que hay que tener en cuenta el papel de los militantes políticos en el proceso de conformación de la clase obrera, también hay que analizar el modo en que los enfrentamientos de clase que marcaron al periodo, con sus flujos y reflujos, marcaron el desarrollo de las corrientes de izquierda que intervenían en el movimiento obrero. El primer impacto en este sentido es el mencionado ascenso huelguístico de 1888-1889, que no solo fue impulsado por los militantes socialistas y anarquistas sino que reforzó su posición en el seno de la clase obrera: Ricardo Falcón (2011) ha señalado que es el momento en el cual los socialistas pudieron "confluir" 
con los trabajadores, y lo mismo cabe decir de los anarquistas. Es un período en el cual, además, se producen numerosas acciones conjuntas entre ambas corrientes políticas. En este cuadro, el acto del $1^{\circ}$ de Mayo representó un salto cualitativo que debe ponerse en relación no solo con el impulso del congreso de París sino con el contexto de ascenso de las luchas que tenía lugar en el país.

El reflujo iniciado en 1890 debilitó a la naciente Federación obrera impulsada por los socialistas: en este sentido se observa un cierto "desfasaje", dado que el avance realizado por los socialistas, con la fundación de la nueva federación y la edición de un periódico, tenía lugar cuando el ciclo de ascenso huelguístico se había cerrado. Es por eso que la Federación atravesó serias dificultades y el movimiento socialista sufrió algunas rupturas en los años 1892 y 1893 . En el marco de este reflujo -agravado además por la salida del país de Errico Malatesta- se produjo también un reacomodamiento en las filas del anarquismo, cobrando fuerza en este periodo la vertiente "anti-organizadora". En efecto, si bien es indudable que el predominio de El Perseguido fue consecuencia de la tenaz actividad de un grupo de militantes de esa orientación, tampoco puede soslayarse que tuvo lugar en un cuadro marcado por el reflujo de las luchas obreras y un debilitamiento de la actividad huelguística.

Cuando se cerró el ciclo de reflujo y volvió a cobrar fuerza la agitación obrera, a partir de 1894, se puso en evidencia que la orientación anarquista "anti-organizadora" se encontraba con serias dificultades para confluir con el ascenso de lucha de los trabajadores. La principal reivindicación de las huelgas del periodo, la reducción de la jornada, era vista por los libertarios como un reclamo "reformista", y por lo tanto rechazado. También se oponían a las huelgas mismas, considerando que eran una medida limitada a los marcos del régimen social vigente y que debía plantearse una alternativa revolucionaria -aunque la estrategia para llegar a ella nunca era explicitada en forma clara. Estos planteos fueron aislando al grupo editor de El Perseguido, que perdió fuerza y activismo en el período 1894-1896: una mirada a sus páginas en ese período muestra su relativo aislamiento respecto a los principales conflictos del periodo, que tienen un seguimiento muy limitado.

En este marco, los socialistas estuvieron en mejores condiciones para empalmar con el ascenso de la lucha obrera. Su fuerte énfasis en la delimitación de una identidad de clase, en la lucha por la jornada de ocho horas y en la consolidación de sociedades de resistencia les permitió confluir con el fuerte ascenso obrero. El proceso de fusión de diferentes grupos y de crecimiento organizativo que conoció el socialismo en estos años no puede separarse del contexto de agitación obrera que lo enmarcó, y al mismo tiempo sus planteos permitieron a los militantes socialistas intervenir, en muchos casos de manera dirigente, 
en diferentes sociedades obreras. Una conclusión importante que se desprende de nuestra investigación apunta a señalar que durante este periodo temprano el socialismo argentino tuvo una fuerte composición obrera y una clara inserción en las sociedades gremiales.

Si la influencia de los anarquistas "anti-organizadores" se vio fuertemente debilitada, los socialistas debieron sin embargo enfrentar el creciente desafio de otro adversario político, que cobraba fuerza en las sociedades gremiales. Por un lado los agrupamientos anarquistas "organizadores", que volvieron a tomar fuerza a mediados de la década de 1890 al calor de la reactivación de la actividad obrera: en torno a periódicos como El Oprimido o L'Avvenire se empezó a perfilar una reorientación de la línea libertaria, que criticaba la actitud prescindente que adoptaba El Perseguido respecto a las huelgas y a los reclamos obreros. Tal como ha señalado Eduardo Gilimón en sus memorias y se pone de manifiesto en las fuentes de la época, todo un sector de anarquistas caracterizó que esa reorientación era indispensable para disputarle al socialismo su creciente influencia sobre las sociedades gremiales.

Por otro lado, es importante destacar el peso que adquirian en el seno del movimiento gremial porteño diferentes sociedades de resistencia que no se alineaban decididamente ni con el socialismo ni con el anarquismo, y ponian en primer plano la necesidad de consolidar las organizaciones gremiales, defender las huelgas y reclamar la reducción de la jornada laboral. Si se diferenciaban de los socialistas porque criticaban su preocupación por la "participación política" y defendian la reivindicación de la huelga general, también se distinguian de las versiones más doctrinarias del anarquismo, al subrayar un componente clasista y defender la lucha reivindicativa.

\section{Conclusiones}

El año 1896 representa el punto culminante de ese nuevo ascenso obrero y al mismo tiempo corona un ciclo de casi diez años durante el cual se produjeron una serie de cambios decisivos en el proceso de formación de la clase obrera local. Durante los meses de invierno y primavera de ese año tuvo lugar una virtual huelga general en Buenos Aires y en Rosario: sin ser nunca declarada como tal, la huelga se extendió de unos gremios a otros a partir de la paralización del trabajo en los importantes talleres ferroviarios. Por un lado vemos cómo la influencia del "contagio" es central, en la medida en que las huelgas en ciertos gremios movilizaban a los trabajadores de otros oficios a salir a pelear por sus reivindicaciones y que el reclamo de reducción de la jornada laboral actuaba como un virtual denominador común en todos los conflictos. Por el otro, vemos que no se llegaron a plantear acciones 
conjuntas de toda la clase, que unificasen el reclamo en un único pliego de reivindicaciones. Existieron en la práctica dos centros de unificación del reclamo obrero: uno en el Prado Español, donde predominaba el elemento anarquista y los gremios de zapateros y panaderos; otro en el local socialista de Barracas, que actuaba como cuartel general de la huelga de ferrocarrileros y mecánicos. Vemos así que la "huelga grande" representó la cristalización de una fuerte tendencia que se venía observando en el período previo, que llevaba a los diferentes gremios de la ciudad a una lucha conjunta por la reducción de la jornada de trabajo, pero que al mismo tiempo no llegó a dar lugar a una huelga general unitaria declarada de manera formal. Esto se debió sobre todo a la negativa de los socialistas, que dirigian en ese momento una Federación obrera, a declarar la huelga general: en todo momento su posición fue contraria a la generalización del conflicto a todos los gremios y primó una postura que sostenía la importancia de concentrar las fuerzas en ciertos oficios que están en conflicto. Entre los anarquistas de orientación organizadora y los sindicatos "autónomos", por su parte, ya cobraba fuerza el planteo de la huelga general, pero no contaban todavia ni con la fuerza ni la organización suficientes para decretar una medida de esas características.

El desenlace de la huelga, por último, impactó sobre el desarrollo posterior de las corrientes. Por el lado del socialismo, creemos que jugó un papel decisivo en el proceso que llevará a Justo a dominar las divergencias internas que habian surgido en el congreso constituyente de 1896 y que le asegurarán el control interno del Partido hacia fines del siglo. La derrota de la "huelga grande", en efecto, fortaleció en la línea del PS la argumentación que caracterizaba a las huelgas como una forma de lucha "primitiva" y de escasa utilidad y ponía en primer plano la necesidad de impulsar la lucha política. Es así como ya a fines del siglo XIX vemos que están cristalizando los elementos característicos del socialismo argentino: por un lado un fuerte énfasis en la necesidad de que los trabajadores tengan su propio partido y desarrollen una lucha política -lo cual implicaba una diferenciación respecto a la Unión Cívica Radical-, por el otro una interpretación de esa lucha politica en clave fuertemente reformista y parlamentaria y una subordinación de la lucha huelguística y reivindicativa, en parte como reacción al peso de los anarquistas en las sociedades gremiales.

Los acontecimientos de 1894-1896 también marcaron en forma decisiva al anarquismo local. El ascenso obrero puso de manifiesto que el planteo de los "anti-organizadores" se revelaba como una traba para una confluencia con el movimiento obrero, y al calor de las luchas de esos años cobró fuerza una nueva generación de militantes de orientación "organizadora", que caracterizó que era necesario intervenir en 
forma activa en las nacientes sociedades de resistencia, en lugar de denunciarlas, e impulsar las luchas reivindicativas de los trabajadores. Los anarquistas de esta orientación confluyeron en muchos casos con militantes gremiales sin una definida pertenencia ácrata pero que se oponían a la política de los socialistas, y en esos años encontramos experiencias como la del periódico La Unión Gremial o la llamada "Convención obrera" de 1896 -un nucleamiento de diferentes gremios adversarios de la Federación obrera dominada por los socialistas, que no tuvo continuidad-en las cuales aparecía ya planteada una orientación clasista y partidaria de la huelga general, al tiempo que hostil a la lucha política que era entendida como sinónimo de participación electoral. En los años posteriores a la huelga de 1896 los militantes anarquistas organizadores cobrarán fuerza en torno a la publicación de La Protesta Humana y aumentarán su influencia sobre el movimiento obrero, al tiempo que, como vimos, el socialismo desarrollaba un movimiento de consolidación de sus posiciones políticas en torno a la línea justista al costo de debilitar su trabajo en el seno de la clase trabajadora.

$$
* * *
$$

Contra lo que podría suponer una primera mirada sobre la abundante producción historiográfica existente, hay mucho por hacer en el campo de la historia de los orígenes del movimiento obrero y la izquierda en nuestro país. La reactivación que se observa en el campo de la historia de los trabajadores podría reactualizar la importante discusión sobre las condiciones de vida que se desarrolló hace varias décadas para luego verse interrumpida. Reivindicamos, en este punto, la tradición de la interpretación "pesimista" y coincidimos con Suriano (2006) sobre la necesidad de que esa interpretación se fortalezca y enriquezca con nuevas investigaciones que le den a esta perspectiva nuevos elementos de juicio y fundamentaciones analíticas. Ello no quita que las nuevas inquietudes de los investigadores actuales le marquen nuevas orientaciones a estos ya antiguos debates: creemos que si la crisis en el campo de la historia de los trabajadores no puede separarse de un contexto histórico marcado por una serie de importantes retrocesos de la clase obrera a nivel mundial -que fueron incluso mayores en el campo político y teórico-, en la actual coyuntura de crisis del capitalismo a nivel global se ha puesto en evidencia una presencia indiscutible de los trabajadores, que pone en cuestión el predominio de una tradición analítica que hablaba del "fin de la clase obrera". Creemos, en fin, que existe por lo tanto una oportunidad y un espacio para que nuevas investigaciones recuperen las herramientas de la historia social sin que eso implique negar la centralidad de la clase obrera. 


\section{Referencias}

Abad de Santillán, Diego (1930), El movimiento anarquista en la Argentina. Desde sus comienzos hasta el año 1910. Argonauta: Buenos Aires.

- (1933), La FORA: ideología y trayectoria del movimiento obrero revolucionario en la Argentina. Buenos Aires.

Aricó, José (1999), La hipótesis de Justo: escritos sobre el socialismo en América Latina. Buenos Aires: Sudamericana.

Bilsky, Edgardo (1984), La Semana Trágica, Buenos Aires: CEAL.

- (1985), La FORA y el movimiento obrero. Buenos Aires: CEAL.

- (1992), "Ethnicité et classe ouvrière: les travailleurs juifs à Buenos Aires (1900-1930)", Le Mouvement Social, n 159, pp. 39-56.

Bourdé, Guy (1973), "La condition ouvrière à Buenos Aires à la fin du XIXe et au debut du XXe siècle", Le Mouvement Sociale, núm. 84.

Camarero, Hernán y Carlos Herrera (2005), "El Partido Socialista en Argentina: nudos históricos y perspectivas historiográficas" en Hernán Camarero y Carlos Herrera (eds.) El Partido Socialista en Argentina: Sociedad, politica e ideas a través de un siglo. Buenos Aires: Prometeo.

Cortés Conde, Roberto (1976), "Tendencia de la evolución de los salarios reales en Argentina, 1880-1910. Resultados preliminares”, Económica núm. 2-3.

Falcón, Ricardo (1979), "Luchas de tendencias en los primeros congresos del Partido Socialista Obrero Argentino. 1896-1900", Apuntes para la historia del movimiento obrero y antiimperialista latinoamericano, año 1 , número 1.

- (1984), Los orígenes del movimiento obrero (1857-1899). Buenos Aires: CEAL.

- (1986), El mundo del trabajo urbano (1890-1914). Buenos Aires: CEAL.

- (2011), "Orígenes del movimiento socialista en Argentina. Prólogo. Capítulo

I y II“. Cuadernos del Ciesal. Año 8, número 10, julio-diciembre 2011, pp 11-45.

Gilimón, Eduardo (1911), Hechos y comentarios. Buenos Aires-Montevideo: Imprenta B. Puey.

Godio, Julio (1972), El movimiento obrero y la cuestión nacional. Argentina: inmigrantes asalariados y lucha de clases 1880-1910. Buenos Aires: Erasmo.

Gutiérrez, Leandro (1981), "Condiciones de la vida material de los sectores populares en Buenos Aires, 1880-1914", Revista de Indias, vol. X-LI, núm. 163-64.

Gutiérrez, Leandro y Luis Alberto Romero (1991), "Los sectores populares y el movimiento obrero en Argentina: Un estado de la cuestión”, Boletín del Instituto de Historia Argentina y Americana Dr. Emilio Ravignani, Tercera Serie, núm. 3.

Iscaro, Rubens (1958), Origen y desarrollo del movimiento sindical argentino. Buenos Aires: Anteo. 
Korzeniewicz, Roberto P. (1989), "Labor Unrest in Argentina, 1887-1907", Latin American Research Review, vol. 24, núm. 3.

Marotta, Sebastián (1960, 1961, 1970), El movimiento sindical argentino. Su génesis y desarrollo. Buenos Aires: 3 vols.

Martínez Mazzola, Ricardo (2004), "Campeones del proletariado. El Obrero y los comienzos del socialismo en la Argentina", Politicas de la Memoria, núm. 4.

Munck, Ronaldo (1987), "Cycles of Class Struggle and the Making of the Working Class in Argentina, 1890-1920”, Journal of Latin American Studies, vol. 19, núm. 1, pp. 19-39.

Nettlau, Max (1927), "Contribución a la bibliografia anarquista de la América Latina hasta 1914", en Certamen Internacional de La Protesta. Buenos Aires: La Protesta.

Oddone, Jacinto (1934), Historia del Socialismo Argentino. Buenos Aires: La Vanguardia.

- (1949), Gremialismo proletario argentino. Buenos Aires: La Vanguardia.

Oved, Iaacov (1976), "El trasfondo histórico de la ley 4.144, de Residencia", Desarrollo Económico, vol. 16, núm. 61, pp. 123-150.

- (1978), El anarquismo y el movimiento obrero en Argentina. Buenos Aires: Siglo XXI.

Panettieri, José (1967), Los trabajadores. Buenos Aires: Editorial Jorge Alvarez.

Paso, Leonardo (ed.) (1974), La clase obrera y el nacimiento del marxismo en la Argentina. Buenos Aires: Testimonios.

Poy, Lucas y Daniel Gaido (2011a), "New Research on the History of Marxism in Argentina", Historical Materialism. Research in Critical Marxist Theory, London, vol. $19, \mathrm{n}^{\circ} 1$.

- (2011b), "Under German Eyes: German Ave-Lallemant and the Origins of Marxism in Argentina". Science \& Society. A Journal of Marxist Thought and Analysis. New York, vol. 75, núm. 4, pp. 480-505.

Ratzer, José (1970), Los marxistas argentinos del 90. Córdoba: Pasado y Presente.

Romero, Luis Alberto (1987), "Los sectores populares en las ciudades latinoamericanas del siglo XIX: la cuestión de la identidad", Desarrollo Económico, vol. 27, núm. 106.

Suriano, Juan (1988), Trabajadores, anarquismo y Estado represor: de la Ley de Residencia a la Ley de Defensa Social (1902-1910). Buenos Aires: CEAL.

- (2001), Anarquistas, cultura y politica libertaria en Buenos Aires, 18801910, Buenos Aires: Manantial.

- (2003), "La crisis de 1890 y su impacto en el mundo del trabajo", Entrepasados, núm. 24-25.

- (2006), "Los dilemas actuales de la historia de los trabajadores", en Jorge Gelman (comp.) La historia económica argentina, cit. 
- (2007), Auge y caída del anarquismo. Argentina, 1880-1930. Buenos Aires: Capital Intelectual.

Tarcus, Horacio (2004), “¿Un marxismo sin sujeto? El naturalista Germán Avé-Lallemant y su recepción de Karl Marx en la década de 1890”, Políticas de la Memoria, núm. 4.

- (2007a), Marx en la Argentina. Buenos Aires: Siglo XXI.

- (2007b), "Entre Lasalle y Marx. Los exiliados alemanes en la Argentina de 1890 y la recepción del socialismo europeo", Politicas de la Memoria, núm. 5.

- (dir.) (2007c), Diccionario biográfico de la izquierda argentina. Buenos Aires: Emecé.

Tarcus, Horacio, Jessica Zeller y Sandra Carrera (2008), Die deutschen Sozialisten und die Anfänge der argentinischen Arbeiterbewegung: Antologie des Vorwärts, (Buenos Aires 1886 - 1901). Buenos Aires: Cedinci Editores-Buenos Libros.

Walter, Richard J. (1977), The Socialist Party of Argentina, 1890-1930. Austin: Institute of Latin American Studies, University of Texas.

Zaragoza Ruvira, Gonzalo (1976), "Anarquistas españoles en Argentina a fines del siglo XIX”, SAITABI, Valencia, Universidad de Valencia.

- (1978), "Anarchisme et mouvement ouvrier en Argentine à la fin du XIXe siècle" Le Mouvement social, núm. 103.

- (1996), Anarquismo argentino 1876-1902. Madrid: Ediciones de la Torre.

Zeller, Jessica (2007), "Entre la tradición y la innovación. La experiencia del Vorwärts en Buenos Aires", Politicas de la memoria, núm. 5.

$$
* * *
$$

Resumen: En este trabajo planteamos una mirada de conjunto a la historiografia existente sobre los orígenes del movimiento obrero y la izquierda en la Argentina. En particular se analiza el modo en el que se planteó el vínculo entre la historia de los trabajadores y la historia de la izquierda. A partir de estas consideraciones proponemos una serie de planteamientos metodológicos sobre lo que creemos un modo enriquecedor de abordar el estudio del desarrollo de las primeras corrientes políticas de izquierda al calor del proceso de estructuración de la clase obrera en Argentina en las últimas décadas del siglo XIX.

Palabras clave: socialismo - anarquismo - huelgas - crisis de 1890

Abstract: This paper offers an overall assessment of the existing historiography on the origins of the labor movement and the left in Argentina. We focus on the way the link between labor history and the history of the left organizations was traced in scholar research. Based on these considerations we suggest a number of methodological propositions for what we consider a new way of approaching 
34 ARCHIVOS de historia del movimiento obrero y la izquierda, $\mathrm{n}^{\circ} 1$

the study of the first leftist organizations and the making of the working class in Argentina in the last decades of the nineteenth century.

Keywords: socialism - anarchism - strikes - 1890 crisis

Recepción: 10 de mayo de 2012 - Aprobación: 9 de junio de 2012 